\title{
Synthesis and characterization of poly(S-2-mercaptoethyl 2-(thiophen-3-yl)ethanethioate) by electrochemical polymerization
}

\author{
Ha Tran Nguyen ${ }^{1,2 *}$ and Le-Thu Thi Nguyen ${ }^{1}$ \\ ${ }^{1}$ Faculty of Materials Technology, Ho Chi Minh City University of Technology, \\ Vietnam National University, Ho Chi Minh City, Vietnam \\ ${ }^{2}$ Materials Technology Key Laboratory, Vietnam National University, Ho Chi Minh City, Vietnam \\ *nguyentranha@hcmut.edu.vn
}

\begin{abstract}
A novel monomer of S-2-mercaptoethyl 2-(thiophen-3-yl)ethanethioate (MTE) were synthesized via esterification reaction between 2-(thiophen-3-yl)acetic and ethane-1,2-dithiol in the presence of dicyclohexyl-carbodiimide (DCC) and N,N'-dimethylpyridin-4-amine (4-DMAP) as catalytic system. The structure of monomer was characterized via $\mathrm{MS},{ }^{1} \mathrm{H}-\mathrm{NMR}$ and ${ }^{13} \mathrm{C}$-NMR spectroscopies. The electrochemical polymerization of MTE monomer was performed in acetonitrile using lithium perchlorate $\left(\mathrm{LiClO}_{4}\right)$ as electrolyte agent. The obtained polymer film (PMTE) was characterized via cyclic voltammetry and it exhibited the main oxidation peaks centered at $+2 \mathrm{~V}$.
\end{abstract}

Keywords: polythiophene, electrochemical polymerization, cyclic voltammograms.

\section{Introduction}

Since the discovery of oxidized polyacetylene that could achieve a very high electrical conductivity, the field of conducting polymers has developed enormously. Nowadays there are many classes of conducting polymers including polyacetylene, polypyrrole, polyaniline, polythiophene and their derivatives. Due to their extremely high conductivity, which results from the delocalization of electrons along the polymer backbone, they are termed "synthetic metals". Besides their notable conductivity, these materials also exhibit interesting optical properties which show dramatic color shifts in response to changes in solvent, temperature, applied potential, and binding to other molecules. Both the changes in conductivity and color of conjugated polymers are induced by twisting of the polymer backbone and disrupting conjugation, making them attractive for their use as responsive electrical and optical devices ${ }^{[1-4]}$.

Among the numerous polymers which have been developed and researched over the several decades, polythiophenes and their derivatives are one of the most interesting classes of conjugated polymers that exhibit advantageous characteristics such as high electrical conductivity, good environmentally and thermally stability ${ }^{[5]}$. The applications of these conducting polymers include non-linear optical devices, polymer light emitting diodes, sensors, organic field effect transistors, organic solar cells, and electrochromic devices $^{[6-12]}$. However, polythiophene has the disadvantage of being insoluble, and hence of being difficult to be processed. Instead, substituted polythiophenes with aliphatic or polar substituents are often used for improving the solubility. Base on that viewpoint, the synthesis of new thiophene derivatives through substitution to the 3 and/or 4 position has opened to exciting new materials with enhanced performances.
For example, incorporation of flexible pendant chains into the backbone improves the processability and solubility, and could also results in polymers having a low oxidation potential and moderate band gap with good stability in the oxidized state. Some other types of substituents reveal thermalchromic, photoluminence behaviors and electrochromic properties ${ }^{[13-15]}$.

In recent years, much attention has been paid to gold nanoparticles due to their potential applications in nanotechnology, such as in single electron transistors or nonlinear optical devices ${ }^{[16,17]}$. Gold-thiol self-assembled monolayers (SAMs) have been widely studied ${ }^{[18-20]}$ because it has high molar absorptivity in the visible region, making them useful for a variety of applications as nanoelectronics, catalysis, molecular recognition systems and developing new optical analytical methods. Therefore, this study aims to synthesize new conducting thiophene-based monomer containing functional thiol group based on S-2-mercaptoethyl 2-(thiophen-3-yl)ethanethioate (MTE). Then, the polymerization of the synthesized monomers was also investigated via electrochemical polymerization technique.

\section{Materials and Methods}

\section{1 Materials}

2-(thiophen-3-yl)acetic, 1,2-Ethanedithiol, dicyclohexylcarbodiimide (DCC), N,N'-dimethylpyridin-4-amine (4-DMAP) and dimethylene chloride, lithium perchlorate $\left(\mathrm{LiClO}_{4}\right)$, Acetonnitril, were purchased from Aldrich. Sodium bicarbonate and chlorohydric acid were purchased from Daejung. 


\subsection{Characterization}

${ }^{1} \mathrm{H} \mathrm{NMR}$ and ${ }^{13} \mathrm{C}$ NMR spectra were recorded in deuterated chloroform $\left(\mathrm{CDCl}_{3}\right)$ with TMS as an internal reference, on a Bruker Avance $300 \mathrm{MHz}$

The cyclic voltammograms were recorded to investigate the electroactivity of the polymer and the oxidation-reduction peak behaviour of the monomer. Acetonnitril (ACN)/lithium perchlorate $\left(\mathrm{LiClO}_{4}\right)$ was used as a solvent-electrolyte couple. The CV system consists of a potentiostat, a XY recorder, a CV cell containing Pt or $\mathrm{Au}$ foil working and counter electrodes, and a $\mathrm{Ag} / \mathrm{Ag}^{+}$reference electrode. The measurements were performed at room temperature under nitrogen atmosphere.

\subsection{Synthesis of S-3-mercaptopropyl 2-(thiophen-3-yl) ethanethioate}

An amount of 2-(thiophen-3-yl)acetic (1 g, $7.03 \mathrm{mmol}$ ), 1,2-ethanedithiol (0.66 g, $7.03 \mathrm{mmol})$, and 4-DMAP $(0.214 \mathrm{~g}$, $1.75 \mathrm{mmol}$ ) was dissolved in $80 \mathrm{ml}$ of dimethylene chloride in a three necked round -bottomed flask. The solution was heated to $60{ }^{\circ} \mathrm{C}$ while stirring continuously under nitrogen. An amount of DCC (2.89 g, $14.06 \mathrm{mmol})$ in $20 \mathrm{ml}$ methylenedichloride was slowly added into the solution. After 9 hours, the solution was filtered and the filtrate was washed with $\mathrm{Na}_{2} \mathrm{CO}_{3}$ repeatedly and dried over $\mathrm{Mg}_{2} \mathrm{SO}_{4}$. The solvent was removed under reduce pressure to obtain a yellow oil. The crude product was purified via a silica column using methylenchloride/methanol (60:1 v/v) as an eluent to yield the pure product as a yellow oil. ${ }^{1} \mathrm{H}$ NMR (300 MHz, $\left.\mathrm{CDCl}_{3}\right), \delta(\mathrm{ppm}): 7.33(\mathrm{~s}, 1 \mathrm{H}), 7.20(\mathrm{~s}, 1 \mathrm{H}), 7.07$ $(\mathrm{s}, 1 \mathrm{H}), 3.86(\mathrm{~s}, 2 \mathrm{H}), 2.92(\mathrm{~m}, 2 \mathrm{H}), 1.87(\mathrm{~m}, 2 \mathrm{H}), 1.56(\mathrm{~s}, 1 \mathrm{H})$. ${ }^{13} \mathrm{C}$ NMR (75.5MHz, $\left.\mathrm{CDCl}_{3}\right), \delta$ (ppm) 196.7, 133.4, 128.8, 126.05, 123.77, 44.92, 37.54, 28.15. MS m/z (M $\left.\mathrm{M}^{+}\right): 232$.

\subsection{Electrochemical polymerization}

Electrodepositions were performed via cyclic voltammetry to study the redox behavior of the monomer and the oxidation stability of the polymer film.

All electrochemical experiments were carried out in a usual, one-compartment cell with a $\mathrm{Ag} / \mathrm{Ag}+$ (in aqueous saturation of potassium chloride) reference electrode (RE) and a platinum wire counter electrode (CE).

Electrodeposition of the MTE monomer was firstly examined by cyclic voltammetry to optimize the polymerization condition. The experiment was performed on a $\mathrm{Pt}$ disc electrode (surface area of $0.03 \mathrm{~cm} 2$ ) from $0.05 \mathrm{M}$ monomer solution in acetonniltrile (ACN) containing $0.05 \mathrm{M} \mathrm{LiClO}_{4}$ by using a potentiostat (parstat 2263).

The obtained the polymer films were rinsed with acetonnitrile $(\mathrm{ACN})$, and were placed into the monomer-free solutions of $0.05 \mathrm{M} \mathrm{LiClO}_{4}$ in $\mathrm{ACN}$ for further electrodeposition measurements, which were conducted potentiostatically at $2.0 \mathrm{~V}$.

\section{Results and Discussions}

\subsection{Synthesis of S-2-mercaptoethyl 2-(thiophen-3-yl) ethanethioate (MTE)}

The mechanism of the reaction between 2-(thiophen-3-yl) acetic and ethane-1,2-dithiol is described in Scheme 1. 3 -thiophene acetic acid reacts with DCC to form $N, N^{\prime}$-dicyclohexylcarbamimidic 3-thiophene acetic acid anhydride which again reacts with another 3 -thiophene acetic acid to create 3 -thiophene acetic acid anhydride and release 1,3-dicyclohexylurea (DCU). Then 3-thiophene acetic acid

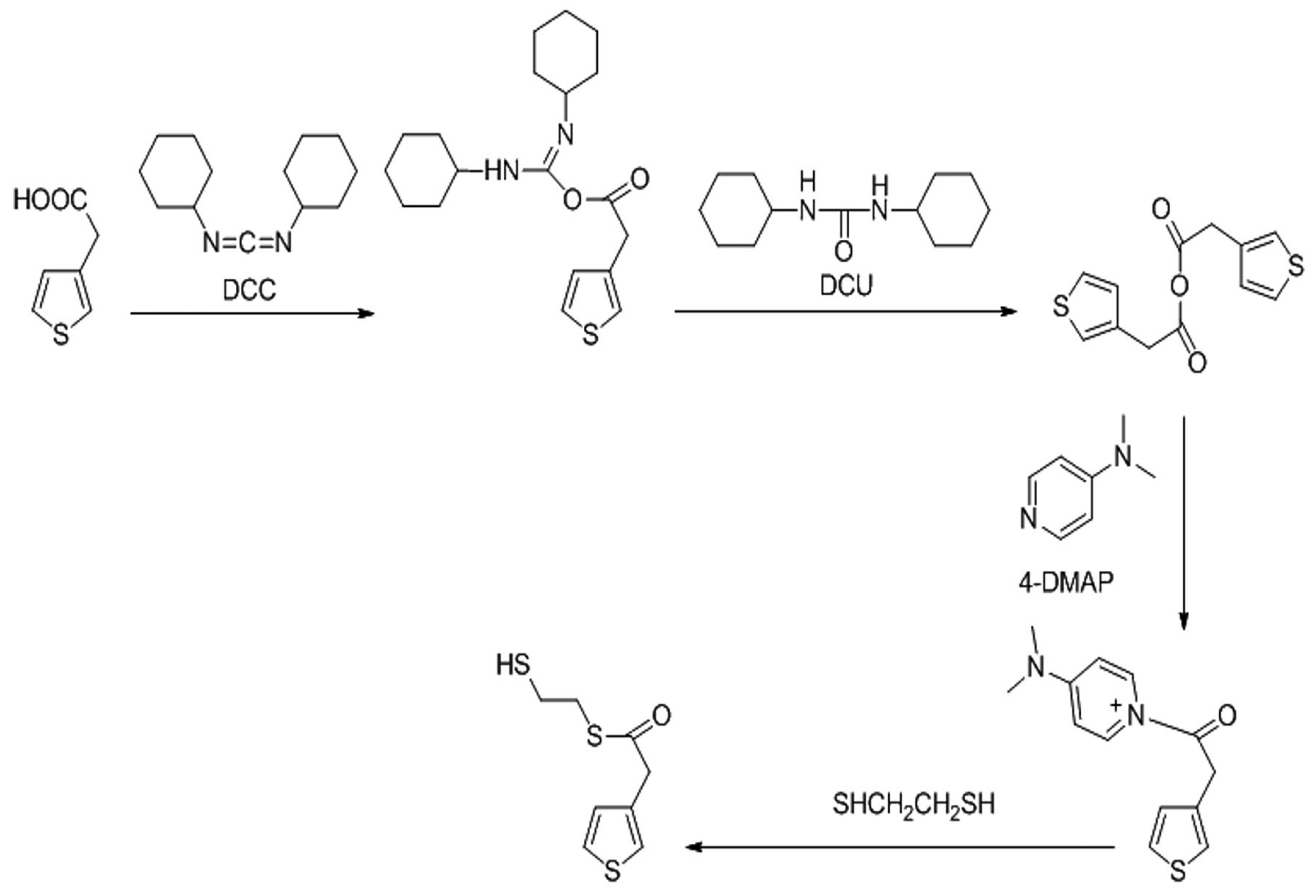

Scheme 1. Synthesis of S-2-mercaptoethyl 2-(thiophen-3-yl)ethanethioate monomer. 
anhydride reacted with 4-DMAP to form an acylpyridinium species. A Nucleophilic substitution appeared on the acyl group by ethane-1,2-dithiol to provide the thioester.

The chemical structure of the synthesized S-2-mercaptoethyl 2-(thiophen-3-yl)ethanethioate monomer was confirmed by
${ }^{1} \mathrm{H}-\mathrm{NMR}$ and ${ }^{13} \mathrm{C}-\mathrm{NMR}$ spectroscopies (Figures 1 and 2). The ${ }^{1} \mathrm{H}$ NMR spectrum shows all charateritic peaks that corresponding to the chemical strucure of monomer, a peak was abserved at $1.56 \mathrm{ppm}$ which contributed to the thiol end group of monomer, and the peaks appear from 7.0-7.4 ppm



d

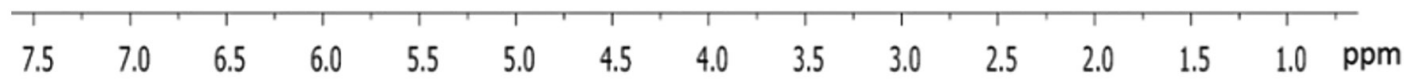

Figure 1. ${ }^{1} \mathrm{H}-\mathrm{NMR}$ of S-2-mercaptoethyl 2-(thiophen-3-yl)ethanethioate.

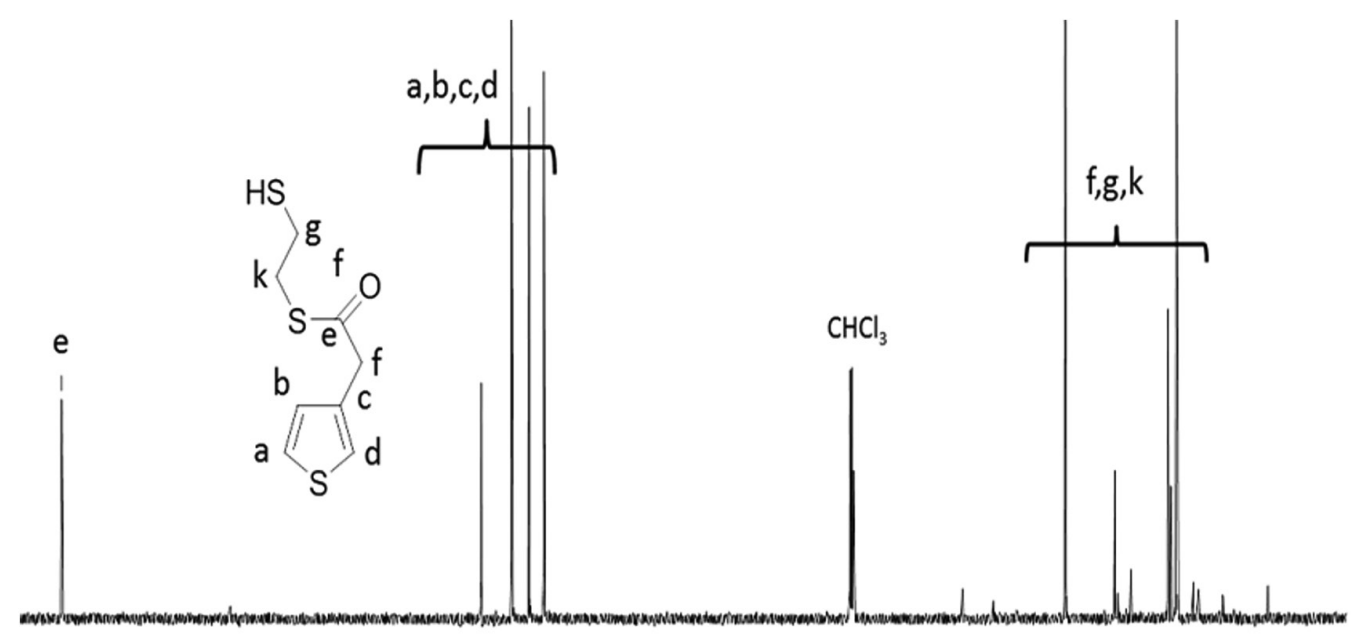

$\begin{array}{lllllllllllllll}190 & 170 & 150 & 130 & 110 & 90 & 80 & 70 & 60 & 50 & 40 & 30 & 20 & 10 & \text { ppm }\end{array}$

Figure 2. ${ }^{13} \mathrm{C}-\mathrm{NMR}$ of S-2-mercaptoethyl 2-(thiophen-3-yl)ethanethioate. 
that corresponding to protons in thiophene ring. The chemical structure of S-2-mercaptoethyl 2-(thiophen-3-yl)ethanethioate monomer was confirmed via ${ }^{13} \mathrm{C}$-NMR which exhibited a peak at $196 \mathrm{ppm}$ corresponding to the thioate group which indicating the formation of a thioester compound.

\subsection{Electropolymerization}

The electrochemical polymerization of the S-2-mercaptoethyl 2-(thiophen-3-yl)ethanethioate (MTE) monomer was successfully achieved shown in Figure 3 that performed in acetonniltrile $(\mathrm{ACN})$ solution containing $0.05 \mathrm{M} \mathrm{LiClO}_{4}$, with a Pt disc electrode (surface area of $0.03 \mathrm{~cm} 2$ ) and using of $0.05 \mathrm{M}$ of MTE monomer solution. The Figure 3 revealed an oxiadation peak at $2.1 \mathrm{~V}$ and a reduction peak at $1.1 \mathrm{~V}$ of monomer, respectively. The film thickness was increasing according to the increasing of scans, denoting the formation of a continuous film on the WE electrode.

After electropolymerization of the S-2-mercaptoethyl 2-(thiophen-3-yl)ethanethioate monomer, the resulting polymer film were continuously measured for oxidative stability by cyclic voltametry in the monomer-free solution in the potential range of 0 to $2.5 \mathrm{~V}$ at different scan rates.

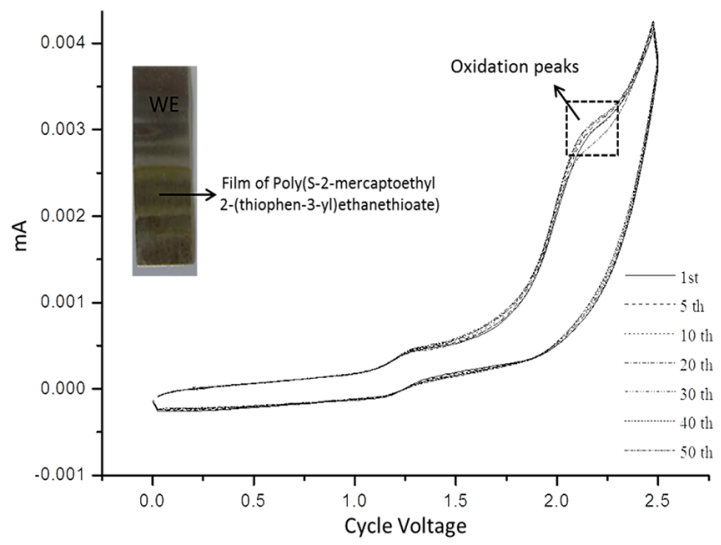

Figure 3. Cyclic voltammograms of S-2-mercaptoethyl 2-(thiophen-3-yl)ethanethioate in acetonnitril.

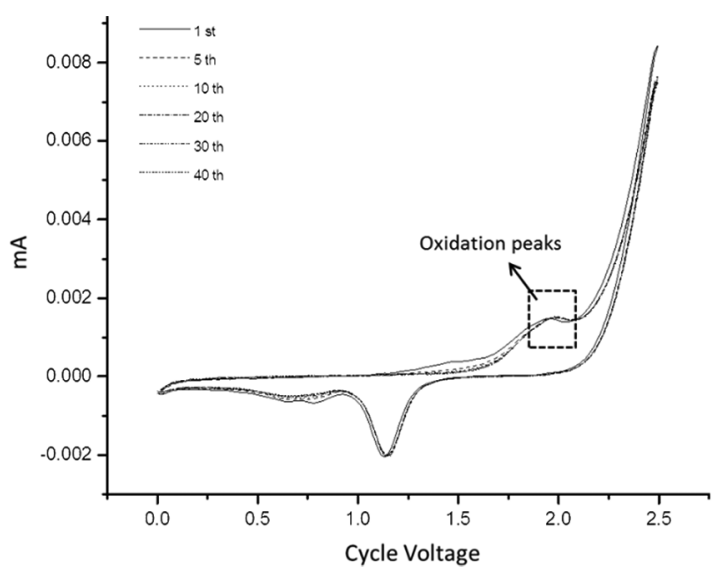

Figure 4. Cyclic voltammograms of Poly(S-2-mercaptoethyl 2-(thiophen-3-yl)ethanethioate).
The obtained polymer films were rinsed several times with acetonnitril (ACN) after electropolymerization process. Following, the polymer film were placed into the monomer-free solutions of $0.05 \mathrm{M} \mathrm{LiClO}_{4}$ in $\mathrm{ACN}$ for characterization. The cyclic voltammogram of polymer film (Figure 4) shows an oxidation peak at $2.1 \mathrm{~V}$ on Pt electrode which contributed to the oxidation peaks of poly(S-2-mercaptoethyl 2-(thiophen-3-yl)ethanethioate). The film of PMTE was very stable during the redox process. Furthermore, the PMTE film showed the same redox potential peaks in its cyclic voltammogram after being stored at room temperature for four months, denoting a good stability of PMTE.

\section{Conclusions}

In this study, a novel monomer S-2-mercaptoethyl 2-(thiophen-3-yl)ethanethioate (MTE) which has a thiol end group was successfully synthesized via esterification of 3-thiophene acetic acid and ethane-1,2-dithiol using DCC and 4-DMAP as catalytic systems. The monomer was found to form electroactive polymer films on the working electrodes, and the polymer films exhibit good stability, reversible behavior and an oxidation potential of $2.1 \mathrm{~V}$.

\section{Acknowledgements}

This research was fully supported by Vietnam National Foundation for Science and Technology Development (NAFOSTED) under grant number "104.02-2013.18".

\section{References}

1. McCullough, R. D., Tristram-Nagle, S., Williams, S. P., Lowe, R. D., \& Jayaraman, M. (1993). Self-orienting head-to-tail poly(3-alkylthiophenes): new insights on structure-property relationships in conducting polymers. Journal of the American Chemical Society, 115(11), 4910-4911. http://dx.doi.org/10.1021/ ja00064a070.

2. Chen, T. A., Wu, X., \& Rieke, R. D. (1995). Regiocontrolled synthesis of Poly(3-alkylthiophenes) mediated by rieke zinc: their characterization and solid-state properties. Journal of the American Chemical Society, 117(1), 233-244. http://dx.doi. org/10.1021/ja00106a027.

3. Bao, Z., Dodabalapur, A., \& Lovinger, A. J. (1996). Soluble and processable regioregular poly(3-hexylthiophene) for thin film field-effect transistor applications with high mobility. Applied Physics Letters, 69(26), 4108-4110. http://dx.doi. org/10.1063/1.117834.

4. Greene, R. L., Street, G. B., \& Suter, L. J. (1975). Superconductivity in polysulfur nitride (SN) . Physical Review Letters, 34(10), 577-579. http://dx.doi.org/10.1103/PhysRevLett.34.577.

5. MacDiarmid, A. G. (2001). Nobel lecture: "synthetic metals": a novel role for organic polymers. Reviews of Modern Physics, 73(3), 701-712. http://dx.doi.org/10.1103/RevModPhys.73.701. PMid:11458347.

6. Roncali, J. (1992). Conjugated poly(thiophenes): synthesis, functionalization, and application. Chemical Reviews, 92(4), 711-738. http://dx.doi.org/10.1021/cr00012a009.

7. Yu, G., Wang, J., McElvain, J., \& Heeger, A. J. (1998). Largearea, full-color image sensors made with semiconducting polymers. Advanced Materials, 10(17), 1431-1434. http://dx.doi. org/10.1002/(SICI)1521-4095(199812)10:17<1431::AIDADMA1431>3.0.CO;2-4. 
8. Welzel, H. P., Kossmehl, G., Schneider, J., \& Plieth, W. (1995) Reactive groups on polymer-covered electrodes. 2. functionalized thiophene polymers by electrochemical polymerization and their application as polymeric reagents. Macromolecules, 28(16), 5575-5580. http://dx.doi.org/10.1021/ma00120a023.

9. Tsumura, A., Koezuka, H., \& Ando, T. (1986). Macromolecular electronic device: field-effect transistor with a polythiophene thin film. Applied Physics Letters, 49(18), 1210-1212. http:// dx.doi.org/10.1063/1.97417.

10. Argun, A. A., Cirpan, C., \& Reynolds, J. R. (2003). The first truly all-polymer electrochromic devices. Advanced Materials, 10(16), 1338-1341. http://dx.doi.org/10.1002/adma.200305038.

11. Huynh, W. U., Dittmer, J. J., \& Alivisatos, A. P. (2002). Hybrid nanorod-polymer solar cells. Science, 295(5564), 2425-2427. http://dx.doi.org/10.1126/science.1069156. PMid:11923531.

12. Arias, A. C., MacKenzie, J. D., McCulloch, I., Rivnay, J., \& Salleo, A. (2010). Materials and applications for large area electronics: solution-based approaches. Chemical Reviews, 110(1), 3-24. http://dx.doi.org/10.1021/cr900150b. PMid:20070114.

13. Ertas, M., Cirpan, A., \& Toppare, L. (2004). Synthesis and characterization of conducting copolymers of succinic acid bis-(4-pyrrol-1-yl-phenyl) ester and their electrochromic properties. Synthetic Metals, 143(1), 49-58. http://dx.doi. org/10.1016/j.synthmet.2003.10.018.

14. Pang, Y., Li, X., Ding, H., Shi, G., \& Jin, L. (2007). Electropolymerization of high quality electrochromic poly(3-alkyl-thiophene)s via a room temperature ionic liquid. Electrochimica Acta, 52(20), 6172-6177. http://dx.doi. org/10.1016/j.electacta.2007.04.015.

15. Groenendaal, L., Jonas, F., Freitag, D., Pielartzik, H., \& Reynolds, J. R. (2000). Poly(3,4-ethylenedioxythiophene) and its derivatives: past, present, and future. Advanced Materials, 12(7), 481-494. http://dx.doi.org/10.1002/(SICI)15214095(200004)12:7<481::AID-ADMA481>3.0.CO;2-C.

16. Novak, J. P., Brousseau, L. C., Vance, F. W., Johnson, R. C., Lemon, B. I., Hupp, J. T., \& Feldheim, D. L. (2000). Nonlinear optical properties of molecularly bridged gold nanoparticle arrays. Journal of the American Chemical Society, 122(48), 12029-12030. http://dx.doi.org/10.1021/ja003129h.

17. Vericat, C., Vela, M. E., Benitez, G., Carro, P., \& Salvarezza, R. C. (2010). Self-assembled monolayers of thiols and dithiols on gold: new challenges for a well-known system. Chemical Society Reviews, 39(5), 1805-1834. http://dx.doi.org/10.1039/ b907301a. PMid:20419220.

18. Nakamura, T., Kondoh, H., Matsumoto, M., \& Nozoye, H. (1999). Recognition properties of the nano-ordered structures of bis(mercaptomethyl)terthiophene monolayers on $\mathrm{Au}$ (111). Synthetic Metals, 103(1-3), 2143-2144. http://dx.doi.org/10.1016/ S0379-6779(98)00602-X

19. Muglali, M. I., Erbe, A., Chen, Y., Barth, C., Koelsch, P., \& Rohwerder, M. (2013). Modulation of electrochemical hydrogen evolution rate by araliphatic thiol monolayers on gold. Electrochimica Acta, 90, 17-26. http://dx.doi.org/10.1016/j. electacta.2012.11.116. PMid:24235778.

20. Civit, L., Fragoso, A., \& O'Sullivan, C. K. (2010). Thermal stability of diazonium derived and thiol-derived layers on gold for application in genosensors. Electrochemistry Communications, 12(8), 1045-1048. http://dx.doi.org/10.1016/j. elecom.2010.05.020.

Received: May 01, 2015 Accepted: Jun. 19, 2015 